\title{
Reliability in Situated Simulations
}

\section{The experience of reality through mediation, and how to document sources and uncertainties in educational sitsim applications of archaeological sites}

\author{
http://dx.doi.org/10.3991/ijim.v7i3.2519 \\ Una Johanne Engmark \\ University of Oslo, Oslo, Norway
}

\begin{abstract}
This paper demonstrates how the mediation of situated simulations (sitsims) might disseminate an enhanced sense of reality for the user - regardless of the actual amount of authenticity in the reconstruction. Therefore, it will be argued, for sitsims to serve their potential as tools for learning, documentation, source criticism and visualisation of uncertainty is key. In order to increase the reliability of sitsims, this paper suggest an extended use of the accompanying website; a continuation of encouraging user-generated links; and more visualisations of alternative interpretations. Additionally, it provides suggestion for further research on ways to improve reliability by 1) allowing users to alter structures without being constrained by fixed values, and 2) employing colourcoding based on level of documentation.
\end{abstract}

Index Terms-Situated simulation, reliability, media aesthetics, visualizing uncertainty, interpretation, digital reconstruction

\section{INTRODUCTION AND MOTIVATION}

Along with advances in technology, research within the field of augmented reality (AR) is rapidly expanding and new areas of use are explored. One example is the ongoing development of situated simulations (sitsim) initiated by the INVENTIO-project ${ }^{1}$ at the University of Oslo. One of the most recent sitsims created is of the Forum of Augustus from ancient Rome.

Historical reconstructions, whether dramatized on stage, painted, written down or virtually visualised, are prone to ambiguity and bias due to lack of documentation. It was therefore interesting to note that university students who tested the Forum of Augustus sitsim seemed to have very different levels of critical reflection with regards to the material presented. While some uttered a strong desire for more information on sources and uncertainties, others seemed to take it at face value without further questioning.

The intention behind sampling students was to explore the potential of sitsim as a tool for learning about culture and history. This paper will review the sitsim in this context. Of the 14 students who answered this section of the questionnaire following the test, nine said that they learned more through interaction and simulation than from using their regular syllabus. However, one participant preferred the module reading list. He elaborated saying "The syllabus includes published and good sources. This [sitsim] is to a greater extent unclear [...]" and stressed the need for source criticism. In the eyes of this author, it is

$1 \mathrm{http}: / /$ www.sitsim.no problematic that only a minority of the participants questioned the reliability of the sitsim when it is indeed based heavily on interpretation ${ }^{2}$.

This paper will review aspects and features that might undermine or increase the reliability of the sitsim. It will discuss the nature of the mediation itself, and argue that the use of borrowed conventions from established modes of communication might contribute to an enhanced sense of reality for the user. It will therefore continue to argue that source awareness and criticism is particularly important in sitsims. An account will be given of the choices made when the research team encountered missing or inconsistent documentation during the process of reconstructing the Forum of Augustus. Finally, this paper will offer some suggestions on how to improve the reliability of this application and similar sitsims, which might subsequently improve their application as tools for learning.

\section{A. Situated Simulations}

A sitsim is a "multimodal dynamic representation that augments the real place with relevant information needed for different purposes" $[1,175]$. It is mobile, but bound to a specific place through GPS-positioning. Orientation technology allows users to move simultaneously within the real environment (RE) and the virtual environment (VE) displayed on the screen. In contrast to traditional Augmented Reality, situated simulations fall in under the category of Indirect Augmented Reality where the "entire scene inside the device [is] virtual" $[28,810]$. The VE consists of a 3D model, diegetic sounds, and information accessed through hyperlinks. These are available as floating "balloons" (labels) attached to objects in the

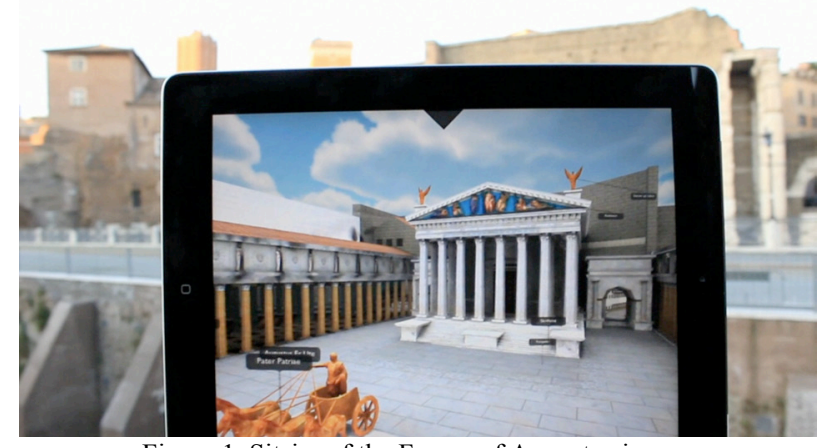

Figure 1. Sitsim of the Forum of Augustus in use. Remaining columns are visible behind the iPad to the right.

2 Albeit one could argue that having previous knowledge of the forum, students are likely to be conscious of alternative interpretations. 
reconstruction. The information is conveyed through voiceover, photographs, text and video. Interactivity is offered through the ability to manipulate the system interface by creating visible hyperlinks for user comments, and the option to choose when, what and how much to read of the information available. In contrast to most AR applications, sitsims offer a clean screen solution when displaying their 3D graphics environments. The mobile device (here iPad2) serves as a virtual camera and the continually changing perspective on screen corresponds to the users point of view in real $\operatorname{life}^{3}[21$, 310-11].

\section{B. The Forum of Augustus sitsim}

The Forum of Augustus sitsim developed as part of the INVENTIO-project was produced and tested/evaluated in 2012. It attempts to recreate the Forum of Augustus ${ }^{4}$ in ancient Rome as an application for iOS. Today, little remain of its grandeur and a significant part of the archeological area is covered by paved roads. With the state of the ruins making it difficult to imagine how it once was, the Forum of Augustus (FA) is well suited for a virtual reconstruction in a sitsim application.

The sitsim is packed with historical and archaeological facts and was evaluated by $14^{5}$ university students who were already familiar with ancient Rome. When they finished testing the application using iPads on-site, the students were asked to answer a questionnaire and to participate in group discussions. The sitsim subject to evaluation was a beta version created on a tight time schedule, and not a finished product.

\section{REALISM VS. REALITY IN VIRTUAL ARCHAEOLOGY}

Within the field of virtual archaeology [3], [4], [5, 183], debates regarding reliability are frequently reoccurring among scholars and practitioners [6, 33], [7, 245], [3]. The crux of the problem is the inevitable fact that archaeology is very much interpretive. As reference [3] points out, the data recovered from archeological excavations and other sources are rarely adequate for a complete virtual reconstruction of buildings and their contents. Providing information on missing documentation, alternative interpretations and meanings, is easy to do in scientific papers, while historic illustrations can alter the perspective or framing to disguise features one does not have sufficient knowledge of. However, missing information in a 3D model has to be covered by interpretations and artistic liberties taken by the modeller [3]. Reference [3] is supported by others when he claims that the nature of 3D rendering - appearing realistic ${ }^{6}$, but often manipulated by creators - subsequently makes it difficult for users to distinguish between the features who were identified by

3 If used correctly with a fully functional GPS-signal.

4 The historical complex was erected by the first emperor of Rome and incorporated a temple in honour of the Roman god, Mars Ultor. At the time of its inauguration in $2 \mathrm{BC}$, the Forum of Augustus was considered a masterpiece, rich in detail, statuary and lucrative materials [2].

5 The total number of participants was 15 , but one student had no previous knowledge of the Forum of Augustus. 6 At least having the potential to do so. archaeologists and historians, and those who are interpretations made during production [3], [8, 187].

With the pressing issue of reliability in virtual reconstructions, several scholars have stressed the need for including descriptions of the data on which the models are based, methods employed and interpretive leaps taken [5], $[7,245]$. Many have proposed suggestions on how to map documentation (see, for example, [7] $)^{7}$. Based on the London Charter, which seeks to establish a cross-national research method for the production of $3 \mathrm{D}$ visualisations [9], [10], [6], InMan (Interpretation Management) offers a framework for mapping documentation with the principle that "[...] all sources are identified uniquely and can be traced easily when needed" $[11,5]$. Neither InMan nor any other standardised framework for source documentation was employed for the FA sitsim. However, a similar function was served through the use of an accompanying website which contained elaborations of information presented. This will be discussed further below.

There appears to be general consensus within the field that virtual archaeology should bring together "all information [available] about a structure or place" $[6,36]$ and - being prone to misinterpretation due to the nature of 3D models - expose the documentation in order to provide a better understanding of the visualisation (e.g. [7, 246]).

\section{MEDIATION AND GENRES CONVENTIONS}

Media Aesthetics is a fairly new methodology within media research. It is based on a perception of aesthetics as the sensory experience one has when faced with an (familiar) object, rather than the more traditional view of aesthetics as judgement of beauty within the (unfamiliar) object itself $[12,29],[13,6-7],[14,43-44]$. As Hausken $[15,15]$ argues, the aesthetic qualities of an object or medium contributes to shaping and influencing what is being communicated. For example, despite containing the same information, looking at a drawn illustration of the Temple of Mars Ultor displayed in a museum, is likely to be experienced quite differently to standing in front of the remains while looking at the $3 \mathrm{D}$ model displayed on the screen of an iPad (see Fig. 2).

It is here argued that media aesthetics is of particular interest in regards to sitsims since this form of

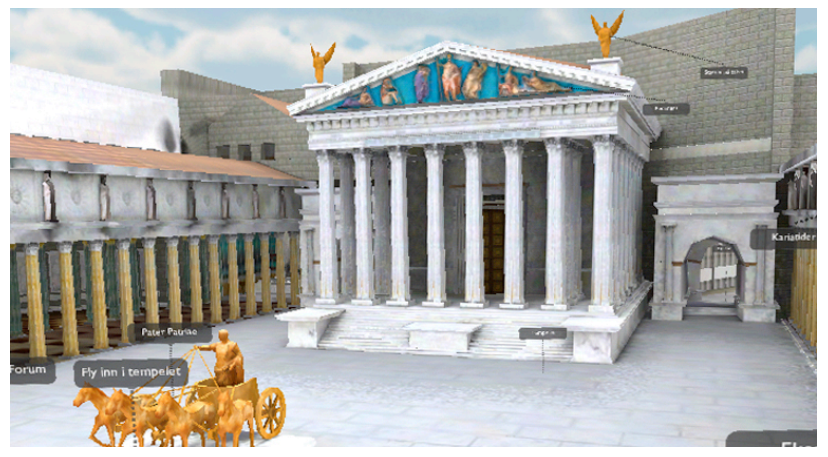

Figure 2. The Temple of Mars Ultor from the FA sitsim.

7 The European Network of Excellence in Open Cultural Heritage strives to create a universal and disciplinary framework within the field, and provides several tools for digital dissemination and visualisation of cultural heritage. 
representation employs several genre conventions from other media ${ }^{8}$. Following, this paper will illustrate how borrowed conventions might evoke connotations connected to familiar media genres - whether consciously or unconsciously - and subsequently create a false sense of reality for the user.

\section{THE DANGER OF MISCONCEPTION}

When asked specifically what they thought of the representation being presented as "fact", 9 the students participating in the evaluation of the FA sitsim answered as following:

- One clearly stated that it is not a definitive.

- One that s/he did not have sufficient knowledge to answer the question.

- Three that they did merely see it as a visualisation of how it might have looked.

- $\quad$ Four pointed out the danger of misconception and a need for expressing in the application that the sitsim is a suggestive reconstruction based on a selection of interpretations.

- One that $\mathrm{s} /$ he did not reflect on it during testing, but that it perhaps should be clarified that it is not.

- $\quad$ Four thought it was fine.

Of the four who were happy with the representation (even when being confronted with its ambiguity) one wrote: "Good, it's fun to see how it looked." Another stated: "That's how it has to be. Seeing as it's the only option really."

Broaching the issue of reliability, this paper will demonstrate and argue that there are in fact several ways to incorporate uncertainties in sitsims. Second, this author believes that it is problematic that more than one third of the students found the sitsim satisfactory - even when being informed of the production background and possible lack of qualifications among researchers. The matter of fact is that this simulation is indeed somewhat one-sided for being an educational tool ${ }^{10}$.

As will be elaborated below, the mediated experience perceived from a sitsim might generate an enhanced sense of reality in the material presented - regardless of actual authenticity. If this is the case, and particularly in a didactic setting, exposing sources and uncertainty is crucial to the reliability of the sitsim. One can argue that in the context of being a tool for students partly educated within the subject field, they should be able to remain critical towards the material presented. However, the data

8 Genre is by reference $[16,79]$ defined as "an expectable form that materials in a given medium might take." By media is here meant any form of communicating a message from one part to another, be it museums, video games, books, chocolate paper or something else.

9 Due to little mentioning of alternative interpretation and lack of information of undocumented features.

10 Much due to time constraints during production. collected from the testing of the FA sitsim suggest that this might not always be the case ${ }^{11}$.

\section{A. Reality vs. realism in the $3 D$ model}

Reference [3] claims that "in essence, the process of 3D modeling has made virtual reconstructions appear realistic whether or not they accurately reflect how the architecture really appeared in the past." Despite the room for improvement of the $3 \mathrm{D}$ model in the FA $\operatorname{sitsim}^{12}$, a majority of the students found the 3D graphics to be "good" or "very good." During group discussions, participants said that the use of 3D resulted in a completely different experience compared to looking at a 2D representation - supporting claims from both virtual archaeology and media aesthetics. As one student put it: "What you see becomes very real because it looks real."

As noted, [3] points out that reconstructing history through a $3 \mathrm{D}$ model makes it difficult to hide or avoid unknown aspects. This problem is perhaps even greater when it comes to 3D models incorporated in a sitsim, as users are able to move within the virtual environment and thoroughly explore the model from all possible angles by employing a variety of different functions (see [1]).

Attempts were made to incorporate decorative elements from the forum ${ }^{13}$ through texture mapping, but fast approaching deadlines left little time for thorough research on the area and many artistic liberties were taken for the placement of the few elements included (Fig. 3-4). Both in the questionnaire and during group discussions, several students uttered a desire for more details in the model. As one argued: "It is the amazing details in/on sculptures/columns etc. in the Antiquity that are fascinating, and these need to be emphasized." Its vast amount of elaborate decorations was also among the aspects that made the Forum of Augustus so spectacular when it was still standing [2].

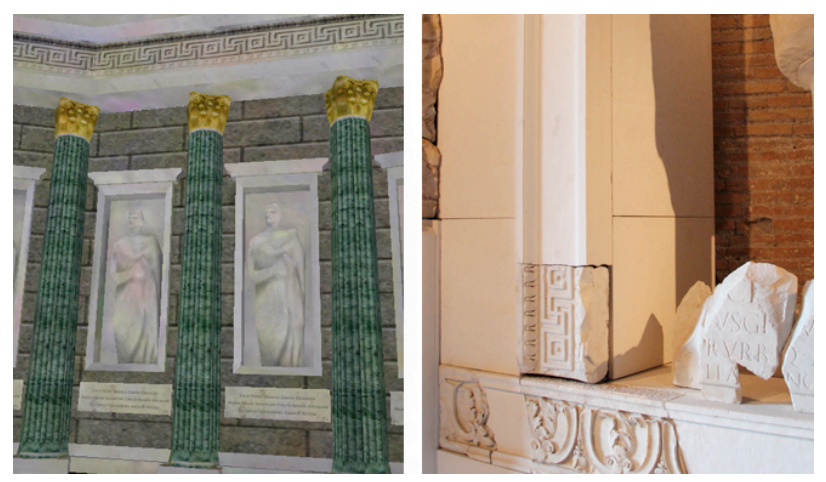

Figure 3. The interior of an exedra in the FA sitsim. The boarder above the columns is textured with a piece found during excavations (Fig. 4).

Figure 4. Archaeological finds displayed at the Museo dei Frori Imperiale, Rome.

11 Although it is important to keep in mind that the empirical evidence used in this report is based on the responses of 14-15 students, and by

no means a representative sample of history students in general.

12 The research team not being able to try the application on-site prior to the evaluation resulted in minor errors regarding measurements and calibration. Additionally, the processor of the iPad 2 placed restrictions on polygon count, which arguably resulted in the $3 \mathrm{D}$ model being somewhat rough around the edges.

13 Exhibited at the Museo dei Fori Imperiali, Fig. 4. 
It is clear from this project that given more time, modellers could relatively easily have improved the authenticity in details of the 3D model. If properly placed and visualised, they would increase the reliability of the model. The details would perhaps also contribute to a better understanding of the forum, increasing the educational value of the sitsim.

\section{B. Features of sitsim and possible experience of reality}

The FA sitsim was based on an existing framework developed as part of the ongoing research in the INVENTIO-project. Prior to the production of the FA sitsim, the framework consisted of ten basic features and functions (see [1]). In addition to these, new functions were added in order to both tackle the lack of accessibility on-site and to improve user interactivity. This paper argues that some ways in which the material is mediated might cause users to more easily view the reconstruction as gospel.

\section{1) On-site}

When asked what genres sitsim might bear resemblance to, several students claimed the nature of movement within the graphics of the VE gave associations to video games. They claimed that being able to use the application off-site, if possible, would support this. Evoking the feeling of playing a video game, one could argue that navigating in a $3 \mathrm{D}$ environment might create a sense of fiction rather than fact. However, instead of sitting in a classroom, the sitsim has users situated on the actual location (Fig. 5). Walking around the ruins, one might be more inclined to be convinced by the reconstruction. As a matter of fact, several students compared the sitsim to guidebooks - providing a sense of being shown the before and after - with the application functioning as a transparent overlay over the present. The term interactive guide was raised during discussions, and surely, when being guided on location, one expects to be provided with facts. Therefore, in-situ movement in itself as part of the mediation could enhance the experience of sitsims as reality.

\section{2) Voiceover and zoom}

In addition to the model itself, information within the sitsim is conveyed through balloons marked with titles corresponding to their contents. When accessed, the majority instantly play a voiceover containing the information. This too might support the feeling of being guided in the sense one is when sightseeing on a specific location with a human- or audio guide. A voiceover providing factual information is also a common genre convention of TV documentaries - for instance those of Natural Geographic, which were specifically mentioned during group discussions on associated media. Some also argued that the ability to zoom within the sitsim mimicked the camera behaviour in nature documentaries. Being familiar with these forms of acquiring information and their assumed reliability, the use of voiceover (and zoom) in sitsims might substantiate the mediation's true-to-life feel.

\section{3) Close-ups of artefacts}

During discussions, the application was compared to the interactive screens that can be found in some museums. The link between museums and sitsims was also made due to the aspect of walking around - though some argued against this comparison. The FA sitsim displays close-ups of artefacts found during excavations of the forum (Fig. 6) ${ }^{14}$, which is undoubtedly reminiscent of museological practices. With museums likely to be considered as institutions displaying pieces of historical truth, this feature of the application might also contribute to overall experience of - though possibly not consciously - the sitsim as communicating facts.

\section{4) In-app photography (now and then images)}

One of the new functions introduced in the FA sitsim was the ability to take a photograph of the VE displayed on top of the RE, using the built-in camera of the device (Fig. 7). Not only are the images displayed together in one frame as the past and present of the FA, but snapshots are something one would normally take of motifs existing in real life.

As demonstrated, employing all of these genre conventions in features might contribute to convey an enhanced sense of reality, not necessarily corresponding with the archaeological data and sources on which the sitsim is based.

\section{5) User-generated comments}

As noted, the sitsim application of the Forum of Augustus offers several aspects of user interactivity. With regard to the question of reliability, it is the ability to create new hyperlinks (balloons) within the VE which is of interest. User-generated balloons differ slightly in appearance from those of the permanent kind, and are available to all individuals using the same login details. Of the 11 test participants who created balloons, eight did so in connection to assignments given within the sitsim. One assignment asked students to point out possible errors they encountered or comment where they might have had alternative interpretations. Three participants said that they created balloon links on own initiative. Six of the 17 user comments created during testing of the sitsim concerned errors in the visualisation ${ }^{15}$ and demands for information on areas not covered. In the questionnaire

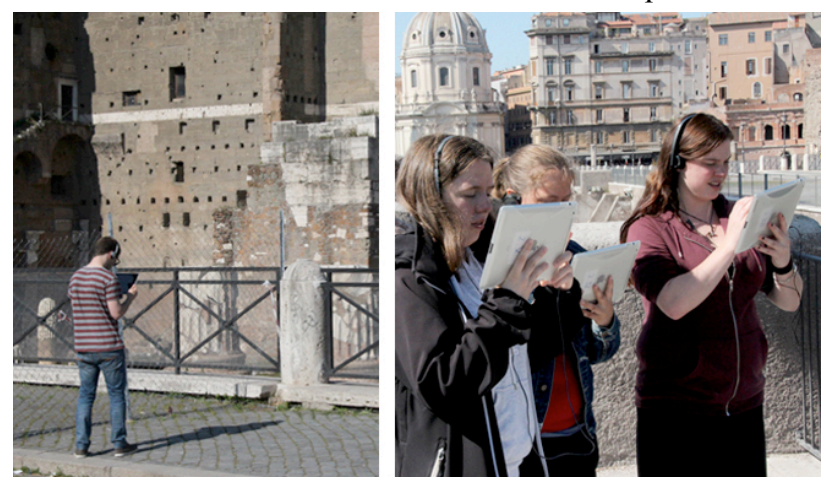

Figure 5. Students testing the Forum of Augustus sitsim on-site.
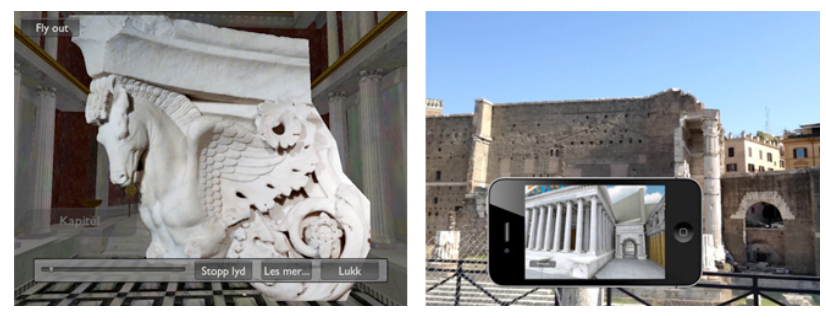

Figure 6. Close-up of volute from inside the temple. Figure 7. In-app photography.

14 These were accessible through balloon links.

15 Albeit covered in writing by the research team in hyper links. 
following the test, one participant said it was "very good that one has the opportunity to comment if there are any errors in the reconstruction or information." This implies that interactivity can function as a tool for users to contribute to the reliability of and healthy criticism towards the sitsim.

However, users might not always be in a state of mind where they remember to critically reflect on and question the information presented - even though encouraging them to comment on errors seems to be helpful. The students who participated in the evaluation of the FA sitsim knew that it was a beta version. They knew it was created by people who did perhaps not possess adequate knowledge of the Forum of Augustus and its history. Nonetheless, a minority made corrections and, as mentioned above, many of the students simply accepted the reconstruction presented ${ }^{16}$.

\section{DOCUMENTATION OF SOURCES AND VISUALISATION OF UNCERTAINTIES}

With the mediated experience of a sisim possibly generating an enhanced sense of reality in the material presented - regardless of actual authenticity - the importance of documentation is crucial for the reliability of the application. As source [11, 5] points out, the reliability of virtual reconstructions is dependent on sources being easily available. Raising awareness of certainties and uncertainties is vital in a didactic context in order to avoid students being mistaught. During evaluation, several participants said that the FA sitsim would benefit from informing users of its interpretive nature.

\section{A. Accompanying website}

No standard framework for documentation of sources was applied to the FA sitism. However, the InMan- and London Charter mindset was implemented through the use of a custom-made website ${ }^{17}$. Accessible through the balloon links under a "Read more" caption, the website offered elaborations of the information given in the 30 seconds long voiceovers. Not only did the posts include the spoken words in written text, but additional text, quotes, images and URL addresses were provided. References for each topic were listed following the information.

Time restraints on the production of this beta version did not leave much room for extensive research to be conducted for the website. The application could easily have been made more reliable by investing more time on completing it.

11 out of 15 students used the website when testing the FA sitsim, but only one claimed to give it a thorough read. Being on-site exploring the sitsim might explain why most did not spend time on in-depth reading. What is interesting to note with regards to reliability, is that 12 out of 14 said they would like to access the website outside of the application - mostly to read and use links and references, but some would also like to add to the content by leaving comments. Unfortunately, the URL of the

${ }^{16}$ Still, the skepticism displayed by these test participants might be greater than it would be for someone not familiar with the researchers behind the sitsim.

17 Created using WordPress (http://wordpress.com/). website was not visible when accessed through the application. The source documentation and reliability of the sitsim would therefore benefit greatly from displaying the address of the website in order for users to make use of it off-site.

\section{B. Visualising alternative interpretations}

Roberts and Ryan [8] state that "users will be better served by systems that enable them to explore and understand different viewpoints." In the process of reconstructing the FA several uncertainties were encountered from what was presumed to be trustworthy sources. Some resulting from speculations due to lack of scientific evidence, such as whether the porticoes were covered with flat wooden roof structures or a barrel vault $[17,136]$, others due to sources presenting conflicting claims regarding, among other things, the sculptural ornaments on the roof of the temple [18, 204], [17, 138], [19] and the statue in the Hall of the Colossus [2, 86], [20]. One book on the FA also included new information about the remains of a third exedra, which was only first discovered during recent excavations [2, 107-8]. The principal task in the reconstruction was to choose what to incorporate and how to present it.

Reference [7, 246] claims that incorporating uncertainty and alternative interpretations would "enhance the educational and dissemination objectives of public presentations." He continues stating that the capability of virtual archaeology to present interpretations other than the authoritative view has yet to be thoroughly explored.

1) Third exedra as alternate view through balloon link

Recent excavations have identified a third exedra at the south-east corner of the FA. As this is a fairly new discovery, breaking with the majority of established sources on the forum, a decision was made to not incorporate the exedra ${ }^{18}$ permanently in the simulation. Instead, users have the opportunity to access an alternate view of the $3 \mathrm{D}$ model with the third exedra present. By enabling the link entitled "Exedra 3 \& 4" a part of the portico's outer wall automatically dissolves, allowing the third exedra to come into view as it appears (Fig. 8). Columns facing the forum space are temporarily rendered with a low percentage opacity in order to better display the change. Within this mode, users could then walk up and have a closer look.

The reconstruction of the third exedra involved a vast degree of interference by the modeller, as little is known other than its radius $[2,107-8]$. With questions regarding interior and number of floors being left unanswered, the exedra was reconstructed similar to the others, though smaller, without a central niche and first floor. The alternate mode was successful in conveying a new interpretation of archeological findings, but the lack of knowledge regarding its function and appearance was not satisfactory communicated. Suggestions on how to tackle this will be discussed later.

As for the other conflicting interpretations mentioned, time constraints forced the research team to decide on one $^{19}$, without offering alternate views of the others.

18 Nor its assumed mirrored counterpart on the opposite side.

19 The most frequently repeated. 

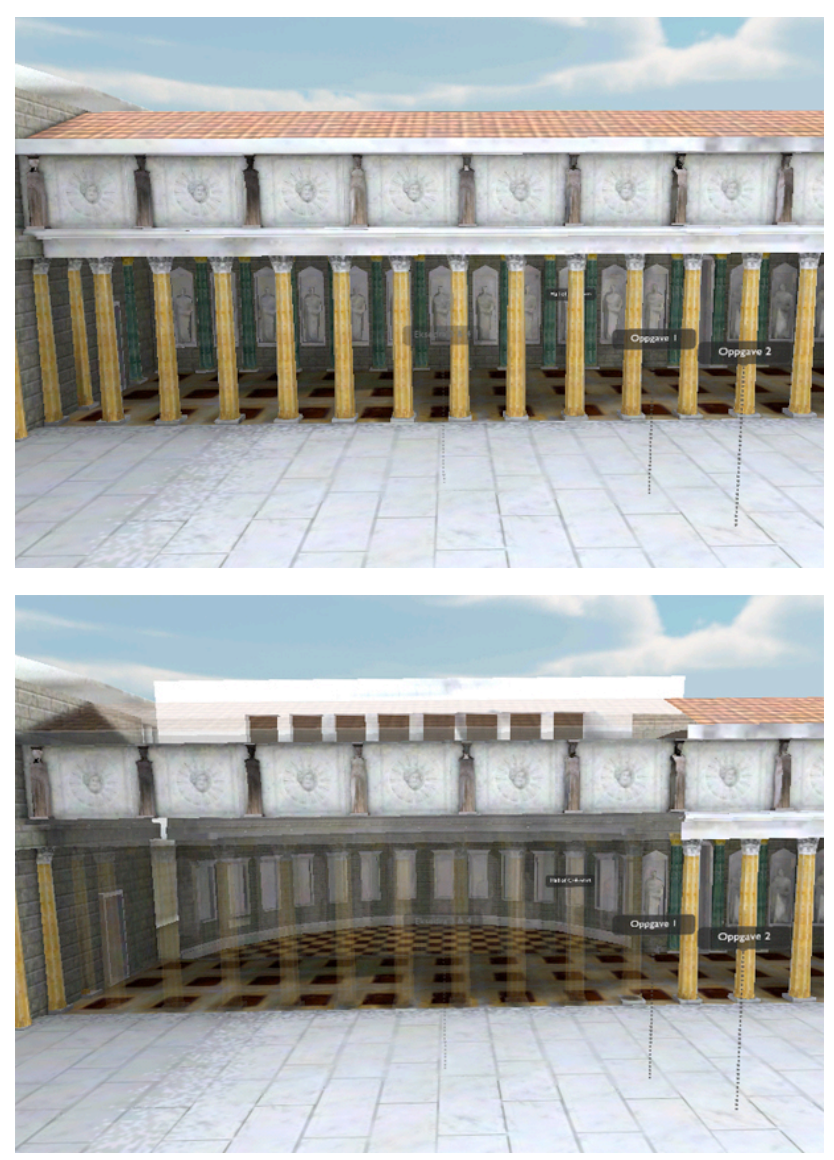

Figure 8. Top: Regular view of portico. Bottom: Alternate view revealing a 3rd exedra.

However, aspects of prominent uncertainty were always mentioned in the voiceover connected to the object/structure in question - if not in great detail. During testing, one of the students aired appreciation of the wording of the voiceover connected to the third exedra. It clearly stated that little is known about it, and that one can only assume a fourth exedra existed based on knowledge of the Romans' liking of symmetry, not from archaeological findings. In order to enhance reliability, this voiceover, as the others, provided users with the option to read more on the website.

In group discussions following the testing of the FA sitsim, one student said that additional interpretations would help to imply that the representation within the application is merely one out of several possible versions. Therefore, visualising interpretations and uncertainty could increase the reliability not only by incorporating multiple sources, but perhaps also by evoking awareness and critical reflection among users.

\section{SUgGeStions FOR FUTURE WORK TO INCREASE RELIABILITY}

So far, this paper has illustrated how the $3 \mathrm{D}$ model in itself and the mediation of information within a sitsim might generate an experience of the presented material as reality. It has also demonstrated the following; how the reliability of the model can be increased by including archaeological findings in texture mappings; how sources are and can be further documented using the website; and how the voiceovers are used to note uncertainty. This paper has found that there is room for improvement of the website, and that reliability could be increased by making it available for use outside the application. Additionally, it has been demonstrated how alternative interpretations can be successfully incorporated as $3 \mathrm{D}$ models in alternate views, and the paper has suggested that the reliability of the sitsim might benefit from visualising more of the different interpretations available.

\section{A. Alteration by users to visualise uncertainty}

In addition to the use of alternate views employed in the FA sitsim, one might consider exploring user alteration as a means to visualise uncertainty and emphasize the interpretive nature of the reconstruction. Reference [8, 183-184] has introduced the Functional Change model, which allows users to manipulate and alter certain parts of a 3D model without being limited by predefined or fixed values. In this way, users can freely alter and explore structures that are undocumented, such as the length of the forum or height of the exedras. The number of columns and stairs are known in the Forum of Augustus, but these might be objects suitable for user alteration in similar sitsims.

The iPad2 processor places restrictions on detail (polygon count) and therefore a limit to the number of $3 \mathrm{D}$ representations of alternative interpretations one can incorporate. However, improvements have already been made with the quad-core graphics processor for iPad $3^{20}$, and Apple is likely to continue the development of processors able to tackle more processor intensive tasks and graphics.

\section{B. Visualising uncertainty using colours}

With the current sitsim interface it is not ideal to link information to every object/structure where one interpretation was chosen over another - too many balloon links are likely clutter the $\mathrm{VE}^{21}$. Different ways of visualising uncertainty have been employed within several fields of scientific research, such as astrophysics [22], [23] and meteorology. Opaqueness (transparency) is one example of uncertainty visualisation previously used in virtual archaeology [24].

Resource [26, 19] propose "visual markings of the objects represented in a $3 \mathrm{D}$ scene that correspond to the type and content of their documentation [...] [as] an indication on what information the proposed shape is based on." Reference [25] has explored the use of a temporary, gradually fading, red texture overlay to emphasize landmarks (RE on-site remains) in the VE of sitsims. A colour-coded documentation layer - as a development of the red textured landmarks - could decrease the danger of students being mistaught and increases the reliability of the sitsim. Taking the red textured landmarks a step further, one could create a colour-coded layer based on the level of certainty attained from available documentation. This could be visualised as temporary changes to hues of textures in the 3D model. Colour-coding would for example be useful for displaying uncertainties with regards to the interior of the third

20 And the more recent dual-core Apple A6 processor for iPhone 5.

21 A solution might be to distribute balloon links over several link-

layers one could switch on and off, but this discussion is not within the

topic of this paper. 
exedra (Fig. 9). For the FA and similar sitsims, there are five different levels of certainty that should be visualized:

- Remaining - on location.

- Documented - no longer on location.

- Partially documented - details unknown ${ }^{22}$.

- Not documented - interpretation by modeller.

- Interpretation - one of several interpretations.

Reference [25, 176] suggests further research on making emphasized landmarks visible early or throughout the simulation. A documentation layer should be accessible from the menu along with the other functions, making it easy to use from anywhere within the simulation. Students testing the FA sitsim aired a desire for an early notion of the interpretive nature of the application, and it is here suggested that an explanation of the documentation layer should be displayed covering the entire screen upon launching the application.

I is important to keep in mind that hue, saturation and contrast are difficult to make out on the screen of the iPad when in sunlight. It would therefore be important to allow users to move within the VE while the colour-coded documentation layer is visible.

The above mentioned suggestions are offered as a starting point for further research and experimentation, and by no means presented as ultimate and final solutions. It is also likely to be other, perhaps better solutions to visualise uncertainty and increase the reliability of sitsms. This paper merely aims to enlighten the issue with regards to educational applications, and hopes to encourage further exploration of methods to handle it.

\section{CONCLUSION}

This paper has demonstrated how mediation can affect the experience of the information conveyed in sitsims. It has argued that it subsequently is important to expose sources, uncertainties and lack of documentation. In the FA sitsim, sources are made available through a website

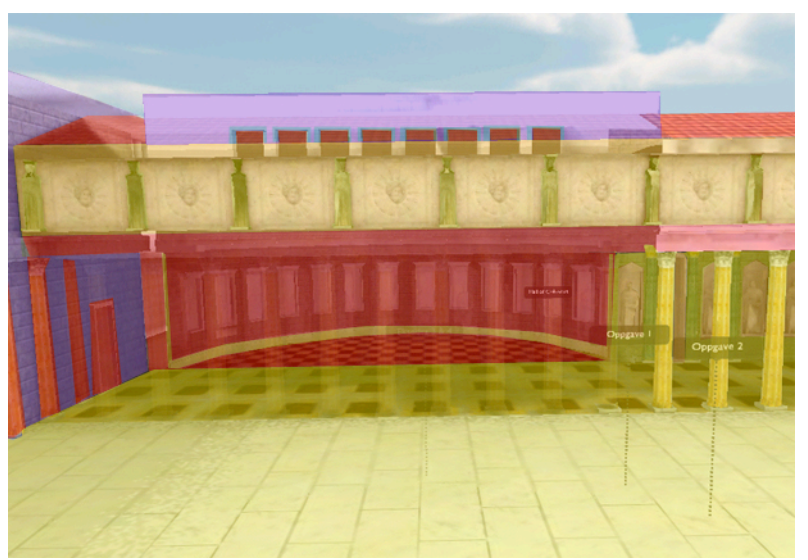

Figure 9. Illustration of how colour-coding might look when applied to the third exedra.

Here: Red = partially documented; yellow $=$ documented; purple $=$ interpretation; blue $=$ not documented.

Made in Adobe Photoshop, not using actual textures.

22 We may know a piece of architecture existed at position $\mathrm{P}$ without

having gathered a serious documentation on it. In parallel, we may have

documented a piece of architecture but without having proposed a morphological interpretation." $[26,21]$ and uncertainty noted in voiceovers. For source documentation to be improved, the URL of the website should be made visible, giving users the opportunity to access it outside the application. Alternative interpretations are to some extent visualised as 3D models, but the sitsim would benefit from this being carried out more often. The ability to create user-generated comments is positive in regard of reliability, and should be encouraged. As suggestions for dealing with the need for further visualisation of alternative interpretations and uncertainties, user alterations inspired by the Functional Change model, and colour-coding are introduced. These suggestions on how to increase the reliability of the sitsim should be further researched and prototyped.

As noted, this account is built on an approach to the sitsim in an educational context. It is important to remember the purpose of communication and intended audience when evaluating the degree and necessity of source criticism and alternative interpretations [3]. The suggestions for improvement presented in this paper might not be needed for a sitsim intended only for tourists ${ }^{23}$.

\section{ACKNOWLEDGMENT}

Without the input, enthusiasm and patience of Professor Gunnar Liestøl at the Depatment of Media and Communication at the University of Oslo, the engineering expertise of Tomas Stenarson at CodeGrind AB, and Šarūnas Ledas' guidance and supporting 3D models, this study could not have been conducted.

Thanks to my fellow students, Andreas Grenasberg, Amund Nitter, Helena Zarifa Pedersen, Maria Brask Sanengen and Julie Vines, for great teamwork. I would also like to thank Magnus Liestøl for photography during testing, my partner Fredrik Gordon Berg, and my brother Hans Alvar Engmark.

\section{REFERENCES}

[1] Liestøl, Gunnar, Terje Rasmussen and Tomas Stenarson. 2011. "Mobile Innovation: designing and evaluating situated simulations." Digital Creativity 22(3): 174-186. http://dx.doi.org/10.1080/14626268.2011.604639

[2] Geiger, Joseph. 2008. The First Hall of Fame - a study of the statues in the Forum Augustum. Leiden: Brill.

[3] Kantner, John. 2000. "Realism vs. Reality: Creating virtual reconstructions of prehistoric architecture." Paper presented at the annual meeting for the Society of American Archaeology, Philadelphia, Pennsylvania, April 5-9. Accessed April 27. http://www.sarweb.org/kantner/SAA00/index.html

[4] Margounakis, Dimitrios. 2008. "Virtual reconstructions in Archaeology." In E-learning methodologies and computer applications in archaeology, edited by Dionysios Politis, 146-156. Hershey, Pennsylvania (PA): Information Science Reference.

[5] Mehta, Mayank. 2001. "Virtual Reality applications in the field of architectural reconstructions." Proceedings of the Seventh International Conference on Virtual Systems and Multimedia (VSMM'01), 183 - 190. Berkeley, California, October 25-27. http://dx.doi.org/10.1109/VSMM.2001.969670

[6] Pletinckx, Daniel. 2011. "Virtual Archaeology as an Integrated Preservation Method." Virtual Archaeology Review 2(4): 33-37. Accessed 12 May. http://varjournal.es/doc/varj02_004_07.pdf

23 Presenting a vast number of interpretations to users unfamiliar with the subject might make the sitsim too comprehensive and difficult to understand. 
[7] Ryan, Nick. 2001. "Documenting and validating virtual archaeology." Archeologia e Calcolatori 12 (7): 245-273. Accessed May http://soi.cnr.it/archcalc/indice/PDF12/13Ryan.pdf

[8] Roberts, Jonathan C., and Nick Ryan. 1997. "Alternative Archeological Representations within Virtual Worlds." Proceedings of the 4th UK Virtual Reality Specialist Interest Group Conference - Brunel University: 179-188. Uxbridge, Middlesex, November 1. Accessed May 25. http://kar.kent.ac.uk/21440/2/Alternative_Archaeological_Represe ntations_within_Virtual_Worlds.pdf

[9] Beacham, Richard, Hugh Denard and Francesco Niccolucci. 2006. "An Introduction to the London Charter." Accessed May 20. http://www.londoncharter.org/introduction.html

[10] Denard, Hugh, editor. "2009. The London Charter - For the computer-based visualisation of cultural heritage," draft 2.1, $\begin{array}{llll}\text { February } & 7 . & \text { Accessed } & \text { May }\end{array}$ http://www.londoncharter.org/fileadmin/templates/main/docs/lond on_charter_2_1_en.pdf

[11] Pletinckx, Daniel. 2008. "An EPOCH Common Infrastructure Tool for Interpretation Management: How to make sustainable visualisations of the past," version 7. Published February 1. Accessed May 20. http://public-repository.epochnet.org/reports/CI_Tool_interpretation_management_v7.pdf

[12] Berleant, Arnold. 2005. "Ideas for a Social Aesthetic." In The Aesthetics of Everyday Life, edited by Andrew Leight and Jonathan M. Smith, 23-38. New York: Columbia University Press.

[13] Leddy, Tom. 2005. "The Nature of Everyday Aesthetics." In The Aesthetics of Everyday Life, edited by Andrew Leight and Jonathan M. Smith, 3-22. New York: Columbia University Press.

[14] Haapala, Arto. 2005. "On the Aesthetics of the Everyday Familiarity, Strangeness, and the Meaning of Place." In The Aesthetics of Everyday Life, edited by Andrew Leight and Jonathan M. Smith, 39-55. New York: Columbia University Press

[15] Hausken, Liv. 2009. Medieestetikk: Studier i estetisk medieanalyse. Oslo: Scandinavian Academic Press.

[16] Agre, Philip E. 1998. "Designing Genres for New Media: Social, Economic, and Political Contexts." In Cybersociety 2.0 Revisiting Computer-Mediated Communication and Community, 69-99, edited by Steven G. Jones. London: SAGE.

[17] Stamper, John W. 2008. The Architecture of Roman Temples: The Republic to the Middle Empires. Cambridge: Cambridge University Press.

[18] Galinsky, Karl. 1996. Augustan Culture: an interpretive introduction. Princeton: Princeton University Press.

[19] Museo dei Fori Imperiali. 2012. "Introduction to the Forum of Augustus." Accessed 19. http://en.mercatiditraiano.it/percorsi/percorsi_per_sale/sezione_del _foro_di_augusto/introduzione_al_foro_di_augusto

[20] Museo dei Fori Imperiali. 2012. "The Hall of the Colossus." Accessed May http://en.mercatiditraiano.it/percorsi/percorsi per_sale/sezione_del _foro_di_augusto/1_aula_del_colosso\#c

[21] Liestøl, Gunnar. 2011. "Situated Simulations Between Virtual Reality and Mobile Augmented Reality: Designing a Narrative Space." In Handbook of Augmented Reality, edited by Borko Furht, 309-319. New York: Springer. http://dx.doi.org/10.1007/978-1-4614-0064-6 14

[22] Botchen, Ralf P., Daniel Weiskopf and Thomas Ertl. 2006. "Interactive visualization of uncertainty in flow fields using texture-based techniques." 12th International symposium on Flow visualization, September 10-14, German Aerospace Center (DLR), Göttingen, Germany. Accessed June 1. http://www.vis.unistuttgart.de/ weiskopf/publications/isfv06_uncertainty.pdf

[23] Li, Hongwei, Chi-Wing Fu, Yinggang Li, and Andrew J. Hanson. 2007. "Visualizing Large-Scale Uncertainty in Astrophysical Data." IEEE transactions on visualization and computer graphics 13 (6): 1640-1647. http://dx.doi.org/10.1109/TVCG.2007.70530

[24] Sifniotis, Maria, Ben Jackson, Katerina Mania, N. Vlassis, Phil L. Watten and Martin White. 2010. "3D visualization of archaeological uncertainty." APGV'10 Proceedings of the 7th Symposium on Applied Perception in Graphics and Visualization, New York: 162. http://dx.doi.org/10.1145/1836248.1836284

[25] Fredheim, Helge. 2010. "Emphasized landmarks for mental calibration in a mobile augmented reality application" In Proceedings of Cognition and Exploratory Learning in the Digital Age (CELDA 2010), edited by Kinshuk et al., 169-176. Timisoara, Romania: IADIS Press. Accessed May 3. http://www.helgefredheim.no/emphasized-landmarks-for-mentalcalibration.pdf

[26] Dudek, Iwona, and Jean-Yves Blaise. 2003. "Access, Interpretation and Visualisation of heritage data using the architectural morphology: experimenting emerging interfaces on a case study." Paper presented at the International Cultural Heritage Informatics Meetings (ICHIM) at L'École du Louvre, Paris, September

$8-12$. http://www.archimuse.com/publishing/ichim03/035C.pdf

[27] Vlahakis, Vasileios, et al. 2002. "Archeoguide: An augmented reality guide for archeological sites." IEEE Computer Graphics \& Applications 22 (5): 52-60. http://dx.doi.org/10.1109/MCG.2002. 1028726

[28] Wither, Jason, Yun-Ta Tsai and Ronald Azuma. 2011. "Indirect Augmented Reality". Computers \& Graphics 35: 810-822. http://dx.doi.org/10.1016/j.cag.2011.04.010

\section{AUTHOR}

U. J. Engmark is an MA student at the Department of Media and Communication, Oslo, Norway. (e-mail: unaje@student.media.uio.no).

Submitted 12 February 2013. Published as re-submitted by the author 26 June 2013. 